\title{
Relationship between Profile Characteristics with Knowledge and Adoption of Transplanting Method of Pigeon Pea Cultivation Practices
}

\author{
Ashok Kumar Melkeri" and Syed H. Mazhar
}

Department of Agricultural Extension \& Communication, Sam Higginbottom Institute of Agriculture, Technology and Sciences, Allahabad, U.P., India

*Corresponding author: ashokkumarmelkeri@gmail.com

\begin{abstract}
The research study was conducted in Kalaburagi district of Karnataka during the year 2014-15 by using ex-post-facto research design. The total sample of 120 was derived from three taluks of a district by using random sampling method. It is concluded from the present study that, transplanting method of pigeon pea cultivation practices is well known among the respondents. It is seen that education, farming experience, land holding, annual income, risk orientation, scientific orientation, extension participation and sources of information showed positive and highly significant relationship at one per cent level, Whereas, innovativeness and mass media utilization showed positive and significant relationship at five per cent level. One variable i.e., age showed non-significant relationship with knowledge level of transplanting pigeon pea farmers. Farming experience showed positive and highly significant relationship at one per cent level, whereas, education, land holding, annual income, innovativeness, risk orientation, scientific orientation, extension participation, mass media utilization and sources of information showed positive and significant relationship at five per cent level. One variable i.e., age showed non-significant relationship with adoption level of transplanting pigeon pea farmers.
\end{abstract}

Keywords: adoption, knowledge, pigeon pea, transplanting, mass media

Pulses play an important role in Indian agricultural economy as they are rich sources of proteins and constitute 10 to 15 per cent of India's food grain diet. Major portion of Indian population belongs to vegetarian group and every person on an average is required to consume 70 to $80 \mathrm{gm}$ of pulses per day in order to maintain good health and physique, according to the recommendations of Indian Council of Medical Research. Pigeon pea [Cajanus cajan (L) Mill sp.] is the second most important pulse crop of India after chickpea. It is cultivated in a multitude of production systems for a diversity of uses - grain as dhal, green seed as vegetable and stalk as fuel wood. It is mainly grown in almost all the states and larger portion of the area is in the states of Maharashtra, Uttar Pradesh, Madhya Pradesh, Karnataka and Gujarat.
India is the largest producer and consumer of pulses in the world contributing around 33 per cent of the world area and 25-28 per cent of world production of pulses. About 90 per cent of the global redgram, 75 per cent of bengalgram and 37 per cent of lentil area is contributed by India. The country produced 19.78 million tonnes of pulses from 17.21 million hectare area, with an average yield of $694 \mathrm{~kg}$ per hectare during 2013-14. These figures make India the largest producer of pulses in the world (www. Indiastat.com). In Karnataka pigeon pea is largely grown in northern parts, especially in Kalaburagi district. Kalaburagi district is called as pulse bowl of Karnataka and pigeon pea is one of the most important pulse crop grown in this region. The agro-climatic conditions are best suited for pulse crops cultivation. The area under pigeon pea crop 
in Karnataka state during the year 2013-14 was 5.95 lakh hectares with the production of 2.57 lakh tones, where as the total area under the cultivation of pigeon pea in Kalaburagi district is 3,70,523 hectares and production is 1,32,987 tonnes. (District at a glance, Kalaburagi, GoK, 2014).

Recent technological intervention of transplanting method of pigeon pea cultivation is one of the alternate agronomic practices to overcome late sowing and related lower yields of pigeon pea, in addition to advantages of low pest and disease occurrence and higher marginal returns. This technique involves rising of seedlings in polythene bags in the nursery for one month and transplanting the seedlings with the onset of monsoon after the soil profile is uniformly wet. Now it is cultivated mainly in Kalaburagi district in the days to come it may occupy larger pigeon pea cultivated area in the state especially in northern parts of Karnataka. It is one of the recently adopted techniques in the study region and gaining importance in pigeon pea farming community. Keeping these things in view, the present study was undertaken to know the relationship between knowledge and adoption level of transplanting method of pigeon pea growers in Kalaburagi district of Karnataka state.

\section{DATA AND METHODOLOGY}

The research study was conducted in Kalaburagi district of Karnataka during the year 2014-15 by using ex-post-facto research design. The study was carried out purposively in Kalaburagi district because the district is considered as pulse bowl of Karnataka state. Kalaburagi district comprises of seven taluks namely, Afzalpur, Aland, Chincholi, Chittapura, Kalaburagi, Jewargi and Sedam. Out of seven taluks, three taluks namely, Afzalpur, Chittapur and Kalaburagi were purposively selected, because highest area of transplanting was done in these taluks. The list of transplanting pigeon pea farmers were taken from Department of Agriculture. A list of villages was prepared for the selected taluks and four villages from the list were randomly selected in each taluk. From each village, 10 respondents were selected constituting a total sample of 120 respondents. Based on the objectives of study, relationship between profile characteristics with knowledge and adoption of transplanting method of Pigeon pea cultivation practices. A list of knowledge items was prepared by discussing with the experts from agronomy, agricultural extension and by referring to the package of practices published by University of Agricultural Sciences, Dharwad. The independent variables namely, age, education, farming experience, land holding, annual income, innovativeness, risk orientation, scientific orientation, extension participation, mass media utilization and sources of information were the main items of investigation. An interview schedule was prepared. The collected data were then analyzed using appropriate statistical tools namely, frequency and correlation.

\section{RESULTS AND DISCUSSION}

\section{Relationship between independent variables with knowledge}

With respect to relationship eight variables namely, education, farming experience, land holding, annual income, risk orientation, scientific orientation, extension participation and sources of information (Table 1) showed positive and highly significant relationship at one per cent level, whereas innovativeness and mass media utilization showed positive and significant relationship at five per cent level, where as variable age showed non-significant relationship with knowledge level of transplanting pigeon pea farmers.

Table 1: Relationship between independent variables with knowledge $(n=120)$

\begin{tabular}{ccc}
\hline $\begin{array}{c}\text { Sl. } \\
\text { No. }\end{array}$ & Independent variables & $\begin{array}{c}\text { Knowledge level } \\
\text { ' } \mathbf{r}^{\prime} \text { value }\end{array}$ \\
\hline 1 & Age & $0.1639 \mathrm{NS}$ \\
2 & Education & $0.2449^{* *}$ \\
3 & Farming Experience & $0.2829^{* *}$ \\
4 & Land Holding & $0.2341^{* *}$ \\
5 & Annual Income & $0.2405^{* *}$ \\
6 & Innovativeness & $0.2213^{*}$ \\
7 & Risk Orientation & $0.2341^{* *}$ \\
8 & Scientific Orientation & $0.2308^{* *}$ \\
9 & Extension Participation & $0.2387^{* *}$ \\
10 & Mass Media Utilization & $0.2174^{*}$ \\
11 & Sources of Information & $0.2336^{* *}$ \\
\hline
\end{tabular}

$r=$ Correlation co-efficient; NS = Non-significant; ${ }^{*}=$ Significant at 5 per cent; ${ }^{* *}=$ Significant at 1 per cent. 


\section{Age with knowledge}

The association between age and knowledge level was found to be non-significantly related with the knowledge level of transplanting method of pigeon pea farmers. This inferred that farmers of different age group had different knowledge level regarding transplanting method of pigeon pea cultivation practices. The knowledge level of younger and middle farmers was higher than old farmers, but this was not significant. The relationship might be because farmers of different age have understood the important practices required. This might have helped majority of farmers to know about the practices at similar level. The above findings are in conformity with Raghavendra (1997).

\section{Education with knowledge}

The association between education and knowledge level of transplanting farmers was found to be positive and highly significant. It is a known fact that, formal education widens the horizons of an individual. In addition, the possible reasons for positive and highly significant association might be that literate people are more receptive and always in search for new information and technologies, which help them to improve their socio-economic conditions. Therefore, transplanting farmers should understand the information learnt from the different sources will be enhanced through education. The above findings are in conformity with Ankulwar (2000) and sawale (2011).

\section{Farming experience with knowledge}

Positive and highly significant relationship with the farming experience with their knowledge level of the respondents. Farmers having greater farming experience understand better about practices. This finding is in close agreement with the findings of Nimje et. al. (1990) in respect of recommended practices. Similar results have been reported by Nemade (2007) and Mane (2012).

\section{Land holding with knowledge}

Land holding was found to be positive and highly significant related with knowledge level of transplanting farmers. This inferred that, farmers with different land holding had different knowledge level regarding recommended practices. With respect to land holding, medium farmers tend to have medium knowledge compared to small farmers. Because, medium farmers having medium land holding and they invest more on agriculture but outcome they got was very less as compared to small farmers. Because, improper management of farm, climatic change and labour problems. Now this transplanting method of pigeon pea cultivation practices is gaining importance in that local area. Therefore medium farmers showing an interest towards this new practice as compare to small farmers with respect to transplanting method of pigeon pea farmers. This finding are in conformity with the results reported by Ankulwar (2000) and Mane (2012).

\section{Annual income with knowledge}

The results revealed that annual income exhibited positive and highly significant relationship with knowledge level about recommended practices in transplanting pigeon pea crop. The possible reason might be that persons respective of their income eager to acquire knowledge through extension contacts and participation in extension activities as well as through their easy access to mass media and had more risk taking ability. The findings are in consonance with the findings of Ramteke (2001) and Sasane (2011).

\section{Innovativeness with knowledge}

Innovativeness with knowledge exhibited positive and significant relationship with knowledge level of transplanting pigeon pea farmers. Innovation decision process necessarily requires knowledge as the first step for adoption of farm technology. This implies that lower the level of knowledge less will be the persuasion of the respondent to adopt or reject innovation. Hence the findings were observed. Similar, findings have been reported by Raghavendra (1997) and Babanna (2002).

\section{Risk orientation with knowledge}

Risk orientation was positive and highly significant related to the knowledge level of the transplanting pigeon pea farmers. This implies that farmers, who had favourable risk orientation towards management and scientific knowledge would like to know new ideas wants to take risks in farming and would try to gather more information which 
could be implied at the field level for increasing production naturally they will prone to acquire more knowledge. The results of the study have also been reported by Nemade (2007) and Sawale (2011).

\section{Scientific orientation with knowledge}

Scientific orientation is positive and highly significant related to knowledge level of transplanting pigeon pea farmers. Good scientific orientation leads to good management orientation. This implies that farmers, who had favorable scientific orientation towards recommended practices would like to know new ideas wants to take risks in farming and would try to gather more information which could be implied at the field level for increasing production naturally they will prone to acquire more knowledge. A farmer with good scientific orientation eager to know the proven scientific practices of recommended practices of transplanting pigeon pea. The findings are in consonance with the findings of Anasuya (1997) and Resmy (1998).

\section{Extension participation with knowledge}

There was positive and highly significant association between extension participation with knowledge of transplanting pigeon pea farmers. The participation in extension activities provides opportunities for contrived experiences and serves as reinforcement in gaining knowledge about recommended practices prevailing in other region or locality. The findings are in conformity with the findings of Kanavi (2000) and Rathod (2005).

\section{Mass media utilization with knowledge}

There was positive and significant association between mass media utilization with knowledge on transplanting pigeon pea farmers. Mass media provide reinforcement, as experiences of successful farmers are also narrated on TV, radio and newspapers. Increased mass media participation enhances the ability of farmers to get more information, which might have helped the farmers to understand and analyse the benefits of recommended practices, leading to higher knowledge. The advent of mass media provided enormous opportunities for repeated exposure of farmer to new technology motivating them to take further interest to learn about them. Hence, those farmers who had positive exposure to mass media had exhibited higher knowledge. The findings are in line with the findings reported by Tippeswamy (2007) and Kharatmol (2006).

\section{Sources of information with knowledge}

Sources of information with knowledge were found to be positive and highly significant association with knowledge level transplanting pigeon pea farmers. The sources of information provides opportunities to get more information on new practices and serves as reinforcement in gaining knowledge about new technology practices prevailing in other region or locality. Medium source of information consultancy enhances the ability of farmers to get medium information, which might have helped the farmers to understand and analyse the new technology practices. Similar, results have been reported Badale (2007) and Sawale (2011).

\section{Relationship between independent variables with adoption}

With respect to relationship, one variables namely, farming experience showed positive and highly significant relationship at one percent level, whereas, education, land holding, annual income, innovativeness, risk orientation, scientific orientation, extension participation, mass media utilization and sources of information showed positive and significant relationship at five per cent level. One variable i.e., age showed non-significant relationship with adoption level of transplanting pigeon pea farmers.

Table: 2: Relationship between independent variables with adoption $(n=120)$

\begin{tabular}{ccc}
\hline S1. No. & Independent variables & Adoption level ' ' $\mathbf{r}^{\prime}$ value \\
\hline 1 & Age & $0.1412 \mathrm{NS}$ \\
2 & Education & $0.2122^{*}$ \\
3 & Farming Experience & $0.2258^{* *}$ \\
4 & Land Holding & $0.2240^{*}$ \\
5 & Annual Income & $0.2262^{*}$ \\
6 & Innovativeness & $0.2109^{*}$ \\
7 & Risk Orientation & $0.2023^{*}$ \\
8 & Scientific Orientation & $0.2098^{*}$ \\
9 & Extension Participation & $0.2200^{*}$ \\
10 & Mass Media Utilization & $0.2023^{*}$ \\
11 & Sources of Information & $0.2030^{*}$ \\
\hline
\end{tabular}

$r=$ Correlation co-efficient; NS = Non-significant; ${ }^{*}=$ Significant at 5 per cent; ${ }^{* *}=$ Significant at 1 per cent . 


\section{Age with adoption}

In concern with relationship between variables with adaption the variable age showed (Table 2) are non-significant relationship with adoption of transplanting method of pigeon pea cultivation practice of farmers. The negative trend indicated that, as age increases the level of adoption of transplanting method of pigeon pea cultivation practice was decreased but not to the significant extent. This is in conformity with the research findings reported by Balasubramani (1997) and Raghavendra (1997).

\section{Education with adoption}

Formal education level of transplanting farmers was found positive and significant related with adoption of transplanting method of pigeon pea cultivation practice. The possible reason could be that higher education of the farmers might have helped them to a larger extent in grasping and retaining the complex agriculture technology. The higher education of the farmers might have made them to get exposed to printed media and department contact i.e., subject matter specialist, scientist and private agency. Many of the transplanting method of pigeon pea cultivation practices require certain amount of scientific knowledge and skills to adopt, which can be easily accepted by farmers who had better formal education than those who lack of it.

Therefore, farmers who had better education, acquired information, resulting in the adoption of transplanting method of pigeon pea cultivation practice. Hence, significant relationship was observed with education and adoption. The above findings are in agreement with the research findings of Kanavi Awale (2000) and Sawale (2011).

\section{Farming experience with adoption}

This variable had positive and highly significant relation with adoption level of the respondents. More the farming experience better will be the understanding of recommended practices which leads to higher level of adoption. Hence, there is highly significant relationship between farming experience of the respondents and adoption level. This finding is close agreement with the finding of Sawale (2011).

\section{Land holding with adoption}

The land holding was positive and significant correlated with level of adoption of recommended practices by the transplanting pigeon pea growers. The probable reason for this kind of result may be that farmers with medium holdings will have more opportunities and potentialities to try and adopt large number of technological innovations. As a result, it is quite possible that farmers with medium holdings evince keen interest to know about new farm practices and be more receptive to such ideas, skills and other management factors, which intern on their extent of adoption of recommended practices. Therefore, land holding must have positive relationship with the extent of adoption of recommended practices transplanting pigeon pea. Deshmuk (2006) and Mane (2012) observed positive and significant relationship between size of land holdings and the adoption.

\section{Annual income with adoption}

Annual income of the transplanting pigeon pea growers was found to have positive and significant relationship with their adoption level of recommended practices. Income of farmers has influenced the adoption of recommended practices; the farmers with low annual income were low adopters, medium annual income with medium adopters and while those with high annual income were high adopters. Generally, the farmers have to invest more when they have to adopt new technology or to follow scientific farm operations. It is also true when it is question of using inputs like fertilizers and chemicals at recommended levels. These inputs cost more than the traditional inputs used by the farmers. Hence, farmers with higher income status can afford investing on such items and adopt most of the recommended practices, while farmers with low income resources cannot afford. This might be possible reason for better adoption of recommended practices by transplanting pigeon pea growers of medium economic status. Similar findings have been reported in the past by Sawale (2011) and Deshmukh (2006).

\section{Innovativeness with adoption}

Innovativeness proneness with adoption was found to be positive and significant associated. 
Innovation decision process necessarily requires knowledge as first step for adoption of farm technology but there was a low innovativeness by the respondents. Transplanting method of pigeon pea cultivation being a new technology practices there is a tendency in farmers to adopt new farm practice, so as to get higher yield and profit, hence the findings were observed. The findings of the study are in conformity with the findings reported by Vasantkumar (2002).

\section{Risk orientation with adoption}

Risk orientation was positive and significant related to the adoption level of the transplanting pigeon pea farmers. This implies that farmers who had favourable orientation towards management and scientific knowledge would tend to be more willing to adopt the latest technology on their field and risk relates to the extent of pains taken by a farmer to achieve greater success than others. Hence risk orientation of farmers has significant effect on their adoption level of recommended practices. The findings are in line with Sawale (2011) and Mane (2012).

\section{Scientific orientation with adoption}

It was evident that the variable scientific orientation was found to be positive and significant relationship with the adoption of transplanting pigeon pea farmers. Scientific orientation is highly significantly related to adoption level on recommended practices by the farmers. Farmers with good scientific orientation will try to adopt all the recommended practices of transplanting pigeon pea. The findings are in line with the findings of Resmy (1998).

\section{Extension participation with adoption}

Relationship between extension participation with adoption of transplanting pigeon pea farmers was positive and significant. The possible reason for this trend may be that, the farmers who had participated in training course, attended meeting, field days, tours, Krishimela might have come in closer contact with extension personnel and other farmers leading to increased knowledge about cultivation practices, which might have motivated them for positive action that is adoption. The other reason could be that extension the participation provides opportunity for farmers to exchange their ideas based on their experience thus leading to higher adoption. The findings of the present study are in conformity with the findings reported by Balasubramani (1997).

\section{Mass media utilization with adoption}

Mass media was positive and significant related with adoption level of the respondents. This might be because of exposure to different mass media sources like television, radio and newspapers might have helped the respondents to gain recent information. The advent of mass media provided enormous opportunities for repeated exposure of farmer to new technology which motivating them to take further interest to learn about them. Hence, farmers who had medium exposure to mass media had exhibited medium level of adoption. Similar, results have been reported by Kanavi (2000) and Kharatmol (2006).

\section{Sources of information with adoption}

Sources of information were positive and significant related to the transplanting pigeon pea farmers with respect to the adoption level. The advent of sources of information consultancy provided enormous opportunities to get huge information on new technology which helps them to take further interest to learn about them. Hence, farmers who had medium consultancy to sources of information had exhibited medium level of adoption. Similar, results have been reported Chavan (2005) and Jadhav (2008).

\section{CONCLUSION}

It is concluded from the present study that transplanting method of pigeon pea cultivation practices is well known among the respondents. It is seen that education, farming experience, land holding, annual income, risk orientation, scientific orientation, extension participation and sources of information showed positive and highly significant relationship at one per cent level, Whereas, innovativeness and mass media utilization showed positive and significant relationship at five per cent level. One variable i.e., age showed non-significant relationship with knowledge level of transplanting pigeon pea farmers. Farming experience showed positive and highly significant relationship at one per cent level, Whereas, education, land holding, 
annual income, innovativeness, risk orientation, scientific orientation, extension participation, mass media utilization and sources of information showed positive and significant relationship at five per cent level. One variable i.e., age showed non-significant relationship with adoption level of transplanting pigeon pea farmers.

\section{REFERENCES}

Dhamodaran, T. and Vasanthakumar, J. 2001. Relationship between selected characteristics of registered sugarcane growers and their extent of adoption of improved sugarcane cultivation practices. J. Extn. Edu., 12(2): 31383143.

District at a glance, Kalaburagi, 2014-15. Directorate of economics and statistics, Government of Karnatka, Bangalore.

Katrarya, S. 1989. Correlates of Adoption Gap of recommended Cotton Technologies among small and big farmers. $P K V$ Research Journal, 27(2): 155-158.
Lakshminarayana, M.T., Krishna, K.S., Manjunath, B.N., Chandrasekar, S. Vaster and Anand, T.N. 2001. Correlates of Adoption of Sustainable Sugarcane Farming practices. Mysore Journal of Agriculture science, 35: 168-171.

Ramesh, P. and Santha Govind. 2008. Extent of Adoption and Relationship between the characteristics of Organic Farmers and their adoption level. Mysore Journal of Agricultural Sciences, 42(3): 526-529.

Sivanarayana, G. and Jayaramareddy, S. 1994. Correlates of Adoption of Recommended Technologies. Indian Journal of Extension Education, 30(1-4).

Vijay Kumar. Khalanche and Gaikwad. 2008. A study of relationship between selected characteristics of the respondent paddy growers and technological gap in the paddy cultivation of Sitamarhi district of Bihar Agriculture Update, 3\&4: 339-341.

www.indiastat.com 
